\title{
Using Six Sigma to Evaluate the Administrative Performance of Vocational and Technical Training Institutions in Jordan
}

\author{
Torki M. Al-Fawwaz ${ }^{1} \&$ Ahmad Badah ${ }^{2}$ \\ ${ }^{1}$ Faculty of Finance and Business Administration, Al al-Bayt University, Mafraq, Jordan \\ ${ }^{2}$ Balqa Applied University, Zarqa, Jordan \\ Correspondence: Torki M. Al-Fawwaz, Finance and Economic Department, Faculty of Finance and Business \\ Administration, AL Al-bayt University, Mafraq, Jordan. Tel: 962-776-714-955. E-mail: alfawwaz@aabu.edu.jo
}

Received: July 4, 2012 Accepted: August 8, 2012 Online Published: October 16, 2012

doi:10.5539/ijbm.v7n20p90

URL: http://dx.doi.org/10.5539/ijbm.v7n20p90

\begin{abstract}
This study aim to identify the using six sigma to evaluate the administrative performance of vocational and technical training institutions in Jordan. The population of the study constitutes from all the administrators, trainers and teachers in vocational and technical training institutes in Jordan which are (758) individuals, a sample was selected in a stratified and random way, consisted of (274) individuals, with a percentage of (36\%) of population of the study. Means and standard deviations were calculated, as well as analysis of variance was used to demonstrate the unilateral differences between the variables of the study and use the Scheffe' test, when there are differences of statistical significance.

To achieve the goal of the study, a questionnaire has been prepared included the fields of (Support and commitment of senior leadership, human resources management, administrative information systems, mechanism of work, practical training and benefices satisfaction) depending on the relevant studies and the system and methodology of Six Sigma, the validity and reliability of the study have been confirmed, the study reached that there is a high degree of estimation for workers who apply the Six Sigma system in vocational and technical training corporations in Jordan. Upon the results of the study, the study recommends that the vocational training corporations should use Six Sigma system in the affiliated vocational and technical institutes and to work on the development of organizational culture based on principles of cooperation and to work in team spirit and maintain on the time and apply Six Sigma methodology to Solve problems and adopt it in the training operations.
\end{abstract}

Keywords: six sigma system, vocational and technical training corporations in Jordan, administrative performance

\section{Introduction}

The world is experiencing a rapid and successive changes and developments in all educational and training corporations distinguished as excellency and search for greater efficiency and proficiency, the administration of corporations find themselves from time to time in front of challenges that imposed the application of upgrade and development for the characteristics of the future, because these challenges directly affect the development of education, which reflects its impact on the educational system in light of globalization and opening up education, also interesting in modern methods of quality does not mean that we are planning to make educational corporations a commercial or industrial facilities seeking to increase their profits by improving their products, but to take advantage of it in education, training and development of conventional methods of educational administration to achieve the quality of the educational and training corporations and seeking for doubling the benefit of society in all its corporations.

To face these challenges, a number of systems and concepts of modern global management have emerged, contributed effectively to the development of these corporations including Six Sigma system which is one of the that modern systems that have evolved and become very widespread in the corporations, which are used to reduce the risk of mistakes by removing differences and reduce errors of the administrative and technical works, using appropriate statistical tools and techniques, where the Six Sigma team are developing the efficiency of services and achieve the desired properties and developing the efficiency and effectiveness of services at the lowest time, effort and cost (Coronado \& Antony, 2002). 
Six Sigma mechanisms also adopt many of the principles that serve as a basis of its strategy, namely: focusing on customer, improve processes and internal activities, decision-making based on facts and data, cooperation and team spirit to work, continuous improvement and prevention rather than inspection.

The fact that Vocational Training corporation in Jordan aims to regulate the exercise of professional and technical work in Jordanian labor market, its vision is seen in accessing to leadership and excellence in the provision of educational services and vocational training and classification of workers professionally according to the needs of the community and the labor market, through training and preparing a qualified and a compete human resources in different vocational specializations through designing, implementing and evaluating training programs with the highest quality standards in partnership with work owners and corporations of civil society within values and principles that focus on teamwork and performance excellence and mastery of work and exercising the participation and transparency systems and the believe that training is for everyone, through Vocational Training corporations related to the foundation which are more than (52) institutes (Vocational Training Corporation, 2011).

Despite this accelerated quantitative expansion made by the Vocational Training Corporation in establishing institutes for vocational and technical training in various cities of Jordan, but it could be argued that this expansion has been accompanied by many challenges, which indicate a decline in the level of training outputs and increase of costs and the existence of an administrative slouch, furthermore the foundation is facing difficulties in the competition and providing services and training products which doesn't commensurate with the size of expenses and facilities, as well as there is a growing reluctance in the demand for enrolling in vocational and technical training in spite of all means of marketing that the institutes followed to attract students, also there are increasing rates of leakage of students and the lack of clarity in the relationship between the corporation and employers as assured by Thiodory (2008) who noted that vocational training institutes is suffering from weaknesses in the application include administrative tasks, governance and that there is duplication in the functions of the corporation, also the private sector believes that the corporation is representing a bureaucratic image with low effectiveness and all powers are concentrated in the hand of the general manager, as estimates showed a decline in the productivity level of training and the inability to respond to Jordanian labor market requirements (Khawaja, 2008).

Also the Jordanian National Agenda (2005) recommended for the restructuring of the Vocational Training Corporation radically in order to achieve the strategic objectives of vocational training institutes to enable the power labors to work in accordance with the requirements of the labor market and increase employment opportunities for people with special needs and contribute to the harmonization of supply and demand in the Jordanian labor market and raising the efficiency and effectiveness of vocational training in accordance with the requirements of the Jordanian labor market and international standards. This study is to identify the assessing of the effectiveness of using Six Sigma system in the development of the administrative performance of the vocational and technical training institutes in Jordan.

\subsection{Problem of the Study}

As Six Sigma is a modern management system and before engaging in the process of applying it effectively in vocational and technical training institutes, this study has to assess the effectiveness of using Six Sigma system in the development of the administrative performance of the vocational and technical training institutes in Jordan to ensure its success and continuation in order to enhance the strengths aspects and to avoid weaknesses aspects, in this context, the problem of the study is determined to answer the following question: What is the degree of assessing the effectiveness of using the Six Sigma system in the development of administrative vocational and technical training institutes in Jordan, so this study seeks to answer the following questions:

1) What is the degree of assessing the effectiveness of using of Six Sigma system in the development of administrative vocational and technical training institutes in Jordan?

2) Are there any statistically significant differences in the significance level of $(0.05 \geq a)$ in the estimating the effectiveness degree of using Six Sigma system in the development of administrative performance institutes of vocational and technical training in Jordan, which attributed to the job title variable (administrator, teacher, coach)?

3) Are there any statistically significant differences in the significance level of $(0.05 \geq a)$ in estimating the effectiveness degree of using Six Sigma system in the development of administrative performance institutes of vocational and technical training in Jordan, which attributed to the years of experience?

\subsection{Objective of the Study}

This study aimed to identify the assessing of the effectiveness of using Six Sigma system in the development of the 
administrative performance of the vocational and technical training institutes in Jordan from the viewpoint of employees within job title and years of experience variables.

\subsection{Significance of the Study}

This study is considered the first study that addressed the issue of six sigma in education and training in vocational and technical corporations, as they also provide the concerned as the owners of the labor market and those who are responsible to these institutes with Six Sigma systems to work on enhancing them through the establishment of strong knowledge base for a continuous success.

\subsection{Limitation of the Study}

This study is limited to administrators, teachers and trainers in vocational training institutes for the academic year (2011 - 2012), it also limited to members of the study sample estimations within the listed fields in the study tool.

\section{Theoretical Framework}

Sigma is known as the eighteenth letter in the Greek Alphabet, it is a statistical symbol of the standard deviation, six sigma is using data under the normal curve for the detection of defects within six standard deviations by (3.4) defect in every million operations (Goh, 2004).

The roots of sigma as a criterion for measuring are referring to (Gauss) who created the concept of normal curve, also Water founded in (1992) Three sigma as a standard of measurement and is based on the ratio of (9.73\%) or (2600) error per million (Raisinghani, 2005), in (1981) Motorola company adopted a Six Sigma methodology and used it to improve products' quality and reduce costs through the calculation of statistical differences in administrative processes and technical control as described by Said (2004) where the company provided (14) billion dollars from (1992-2002) (Goetsch, 2006).

Sigma account is represented for the most activities and administrative, financial and technical processes by the following steps:

- Understand the expectations and requirements of customers; it is called the necessities tree of quality.

- Calculate the number of defects that occur in the process.

- The calculation of the process's output; it is the ratio of items free of defects attributed to all items of the process.

- The use of special statistical tables to determine the level of Sigma, as a result, the level of performance is clear.

Six Sigma methodology is applied through five stages combined in the (DMAIC) model (Hung and Sung, 2011; Garrison, et. al., 2010; Pardee, 2007; Kreisder, 2006; Goffnett, 2004; sung, 2003; Pande \& Holpp, 2002; Chowdhury, 2001; Eckes 2001), using this form, it has been reached to implement the six sigma approach, and these stages are as follows:

1) Problem Definition;

2) By identifying where the problem is? And what are the factors related to quality and to identify the needs and expectations of customers.

3) Measure the Level of Performance;

4) It includes the process of gathering data and information on a particular phenomenon such as the probability of occurrence of defects and their causes.

5) Analyzing the Reasons;

6) It is a process of identifying possible causes of the problem and the differences and defects that affect the output of processes where a team is studying the dimensions of the problem in more detail, using a scientific tools, the most common tools used in this analysis is the cause and result style (Eckes, 2001).

7) Improve;

8) Include a range of activities that contribute in the process of improving performance and raising the level of service in the corporation.

9) Control;

10) This phase includes all the operations or activities that help in controlling the performance by setting the standards development process to maintain the level of quality through finding a constant supervision system to avoid the problem (Kreisder, 2006). 


\section{Literature Review}

There are many studies which dealt with the studying of Six Sigma System, these studies are:

Al-Rihani (2010) study, which aimed to identify the possibility of applying Six Sigma's principles in the school management and the constraints facing the school principal to apply the principles of Six Sigma and the relationship of experience, qualification, type and level of education factors and educational stage with a potential of the application of Six Sigma form by school administrators in the State of Kuwait, the sample consisted of (257) directors that are representatives of all levels of education in all schools in Kuwait, the study used a descriptive approach, the results of the study indicated the existence of some quality systems for schools administrators, and they have a good knowledge to apply it in their school's administration, and have the potential and the necessary powers to implement the model for the Six Sigma mechanism in their schools, also there are many obstacles that do not facilitate the use of Six Sigma such as the traditional understanding of education by the leadership of the ministry and the limited powers and the large workload of the director.

Jenicke (2008) study aimed to examine the challenges of the application of Six Sigma methodologies in educational and academic field, he improved a framework for enhancing the Six Sigma mechanism using an academic performance indicators associated with it in a pyramid scheme in line with the academic corporations levels, and therefore they suggested a model of strategic objectives and performance indicators according to the performance implications of the Demaq model. The results indicated that the characteristic system of the academic corporation can be benefited from the Six Sigma mechanisms, the results show that the proposed system of Six Sigma can be used by different educational systems, such as administrators, faculty and students, the existence of a difference between the academic and economic environment make some difficulties in the application of Six Sigma in the academic field.

As stated in Hement study (2006) that aimed to identify the Six Sigma rules and their uses in education, where the study suggests that Six Sigma is a set of methodologies and approaches used by organizers of the business to get the lowest rates of failure or error in any process, in a similar way which can be used to obtain the overall superiority in the field of education as the Six Sigma is a unified direction of work of superiority and mastery, the study suggests that the strategy should be applied now in the field of education to improve the overall performance of students and the submitted scientific paper have two parts: First: Explains what is Six Sigma? Second: Assume how Six Sigma methodologies can be applied in education? In order to participate in a competitive world, here it is supposed that the customers are the students and that the quality of learning they receive is the provided service, as it can be said that the students here are the product offered by educational institutions to employers, researchers presented a model for the application of Six Sigma in education based on (Demaq) mechanism, from which it can access to the product (students' excellence) that satisfy the labor market and is consistent with the competitive environment.

$\mathrm{Zu}$, and Robbins (2006) study aimed to identify the impact of organizational culture on quality practitioners in the application of Six Sigma, the study focused on five key variables: the direction, organizational groups, development, rationality and hierarchical organization, this study was applied in (226) institutions in Atlanta state, the study reached to the importance of guidance for the organizational groups, development and the rationality of the quality practitioners in Six Sigma, while the hierarchical organization has no role to quality practitioners in Six Sigma.

Weinstein (2006) study aimed to find out how to take advantage of the provision of models for Six Sigma in teaching quality management in universities, the study justified this that the university professors are facing a major challenge in the presenting an effective teaching to the quality management concepts and its tools, most textbooks focus on providing the concepts and theoretical tools for quality management and fail to make a presentation of the complex issues faced by individuals during their solution to the problems, in fact, conventional methods are not sufficient for students to view the challenges faced by professionals in the institutional conditions, so through a descriptive and theoretical inductive approach, the study provided a trend which aims to provide a practical models for the students using a quality management projects to improve operations with Six Sigma mechanism in local companies, in order to enhance students' classroom experience, the project offers good tools to enhance learning and strengthen the links between the university and community economic development.

As stated in Pie-shih study (2006) which aimed to identify the reality of companies in Taiwan that apply Six Sigma and its impact on business performance, the study focused on the following independent variables: Top management support, training, integration of all quality skills, integration of decision-making with the financial situation of the company, the dependent variable performance of the business of reducing costs, reduce errors, increased customer satisfaction and sales growth. The study found that the application of Six Sigma has a positive 
impact on reducing costs and the percentage of errors and there is no relationship between the application of Six Sigma and the increased of sales volume and there is a positive relationship between the application of Six Sigma and the increase of customer satisfaction.

Shaman's (2005) has aimed to identify the concept of Six Sigma and its components, characteristics and importance of administrative leadership in general and how it is used and developing it to suit the educational institutions and the statement of the difference between them and the total quality management, the most important barriers that prevent its implementation effectively, a descriptive and analytical approach was used to study six sigma as they really acknowledge it to be improved and developed using the documentary method to analyze and extrapolate the management literature thought to answer the questions of the study, which found the need to provide Six Sigma within the training programs offered to the educational leaders at various administrative levels and educate workers in the field of education on the importance of the use and application of the principles of Six Sigma.s

\section{Method and Procedures}

\subsection{Methodology of the Study}

The study relied on the descriptive method of analysis to identify the Using Six Sigma to Evaluate the Administrative Performance of Vocational and Technical Training Institutions in Jordan.

\subsection{Study Sample}

The study sample consisted of (274) administrators, teacher and trainer of field training institutes in Jordan, representing (36\%) of the study, they were selected by stratified random way according to the variables of (Job title, years of experience), table (1) shows the study sample by distributors variables (job title, years of experience).

Table 1. Members of the study sample, distributed according to variables of the study for workers in the vocational training institutes

\begin{tabular}{lccc}
\hline Variable & Group & Number & Percentage \\
\hline Job Title & Administrator & 92 & $33 \%$ \\
& Teacher & 43 & $16 \%$ \\
& Trainer & 139 & $51 \%$ \\
Total & & 274 & $100 \%$ \\
Years of Experience & Less than (5 years) & 40 & $15 \%$ \\
& From 5-10 years & 111 & $41 \%$ \\
& More than 10 years & 123 & $44 \%$ \\
Total & & 274 & $100 \%$ \\
\hline
\end{tabular}

\subsection{Population of the Study}

The population of the study consists of all administrators, teachers and trainers of the vocational training institutes in Jordan, which are (758) persons for the academic year (2011/2012).

\subsection{Study Tool}

The study tool was developed on the basis for studies related to the subject of Six Sigma System, where the study tool formed in its initial image into two parts: The first part, which contains a personal information about employees in the vocational training institutes, the second part consists of (42) items to measure the degree of assessing the effectiveness of using Six Sigma system in vocational training institutes, the tool has been designed on five-Likert Scale, which falls under five categories. For the purposes of analyzing and determine responses of the sample, the next gradient of the median estimates of employees in the vocational training institutes were used in the fields of the study tool:

- Arithmetic Means of the estimates of 3.6 and above equal to a high degree.

- Arithmetic Means of the estimates of 2.33 or less than 3.66, equal to a medium degree.

- Arithmetic Means of the estimates of 2.49 or less, equal to low degree.

\subsubsection{Study Tool's Credibility}

The authenticity of tool content had been verified in an approved manner; where the questionnaire has been 
presented to arbitrators with jurisdiction and expertise of university professors, they were (14) arbitrators, (10) arbitrators were responded, their opinions were about the appropriate paragraphs of the field and clarity of the wording of paragraph, the extent of suitable fields and questionnaire's paragraphs for classes presented to them from workers in vocational training institutes and any addition or delete or relevance proposals. (80\%) of the views of arbitrators considered as a standard to judge on the paragraph validity, and after making the amendments that they pointed out by deleting and adding or amending or reforming, so that the tool is become in its final form consisting of (36) a paragraph, included six fields: (The Commitment of Senior Leadership, Practical Training, Human Resources Management, Information Systems Management, Achieving Beneficiaries' Satisfaction and Work Mechanism).

\subsubsection{Study Tool Stability}

To ensure the stability of the study tool, a questionnaire was applied to a sample of (24) individuals from outside the study sample in vocational training institutes, using the test method and Test-Retest with a time lag of (3) weeks between the first and the second applications of the sample itself, where Person's coefficient correlation was calculated between the two applications, the overall coefficient factor has reached in this way to (0.87), this refers to the acceptable degree of stability, which supports the confidence using the questionnaire to achieve the objectives of the study, table (2) shows the stability of the study tool fields and the tool as a whole.

Table 2. Stability coefficients for the study tool and its fields

\begin{tabular}{clc}
\hline Number & \multicolumn{1}{c}{ Fields } & Coefficient Factor \\
\hline 1 & Support and Commitment of the Senior Leadership & 0.87 \\
2 & Human Resources Management & 0.84 \\
3 & Administrative Information System & 0.89 \\
4 & Work Mechanism & 0.81 \\
5 & Practical Training & 0.93 \\
6 & Beneficiaries' Satisfaction & 0.88 \\
Overall Stability & 0.87 \\
\hline
\end{tabular}

\section{Statistical Methods}

The researchers calculate the arithmetic means and standard deviations in order to answer the first question to identify the effectiveness of using Six Sigma System in vocational training institutes by their workers and to answer the second question and the third, analysis of variance was used to demonstrate differences between the variables of the study and using Scheffe' test, when there are differences of statistical significance.

\section{Study Results \& Discussion}

\subsection{Results and Discussion the First Question}

What is the assessing effectiveness of the use of Six Sigma system in the development of administrative performance for vocational training and technical institutes in Jordan?

To answer this question, means and standard deviations had been calculated of estimates for workers of the effectiveness of using six sigma systems in vocational training institutes in descending order, table (3) clarify that.

Table 3. Arithmetic means and standard deviations for the sample member's estimates to their estimations for the use of six sigma system descending rank according to the means

\begin{tabular}{cclccc}
\hline Rank & Number & \multicolumn{1}{c}{ Six Sigma Fields } & $\begin{array}{c}\text { Arithmetic } \\
\text { Mean }\end{array}$ & $\begin{array}{c}\text { Standard } \\
\text { Deviation }\end{array}$ & $\begin{array}{c}\text { Using } \\
\text { Effectiveness }\end{array}$ \\
\hline 1 & 5 & Practical Training & 4.425 & 1.212 & High \\
2 & 1 & Support and Commitment of Senior Leadership & 4.136 & 1.054 & High \\
3 & 2 & Human Resources Management & 3.972 & 0.923 & High \\
4 & 6 & Beneficiaries' Satisfaction & 3.425 & 0.882 & Medium \\
5 & 3 & Management Information Systems & 3.407 & 1.041 & Medium \\
6 & 4 & Work Mechanism & 2.287 & 0.956 & Low \\
Tool as a whole & & 3.625 & 0.878 & High \\
\hline
\end{tabular}


It is noted from table (3) that the total degree's mean for the workers' estimates in the vocational and technical training institutes has reached in an arithmetic mean of (3.625) in a high degree, while the means are ranged for of the Six Sigma methodology fields between (4.425-2.287), by looking to this result, we find that all these fields can be used in a varying degrees (High, medium, low), this result agreed with the study of (Al-Rihani, 2010) and the study of (Jenicke, 2008).

Table (3) shows the descending order to the staff estimations (Administrators, Teachers, Trainers) to measure the effective use degree of Six Sigma System fields, in first rank the field of (Practical Training), reached an arithmetic mean of (4.425), in the second rank (Support and Commitment of Senior Leadership) with an arithmetic mean of (4.136), in the third rank, the field of (Human Resource Management) and got the arithmetic mean of (3.972), in the fourth rank (Beneficiaries' Satisfaction), and obtained the arithmetic mean of (3.425), in the fifth rank field of (Management Information Systems) and got the arithmetic mean of (3.407), while in the sixth and last rank, the field of (Work Mechanism) got the arithmetic mean of (3.387). The results showed that the field of (Practical Training) came in first rank with a mean of (4.425) with a high degree. This indicates that the degree of readiness of employees to implement the Six Sigma program could be the biggest in this field, due to the experience and the pursuit of the institute management in the vocational and technical training for the preparation of all workers, administrators, teachers and trainers in different organizational levels inside and outside the institute, theoretically and practically, to understand and recognize the program and methodology of Six Sigma and accept its concepts and ideas, in order to ensure their cooperation and their commitment and convince them with it, through the creation of a plan to train staff as a team, design and implementation of practical training programs permanently and continuously for workers, in which will be reflected on the students and trainees, through preparation for budget allocation and the provision of places and attract qualified instructors to train workers in those institutes. This study has been agreed with the study of (Motwani \& Antony, 2004).

The results also showed that the field of (Support and Commitment of Senior Leadership) came in second rank, with a mean of (4.136) with a high degree, due to the availability of administrative leadership for the vocational training institutes, their corporations have a clear message and vision, which is capable of applying and implementing a modern administration programs and ready to use statistical techniques to solve problems and work to save time and tools to use the programs and Six Sigma methodology and provide support for it, the results of this study agreed with the study of (Pie-Shin, 2006).

In the fifth rank the (Management Information Systems) with an arithmetic mean of (3.407) in a medium degree, this result might be due to that institutes of vocational and technical training should activate and provide data base and information, where all the facts and statistics relating to all department of vocational and technical training can be stored and provided for those who need it very quickly, which helps to raise and improve the work, as well as working on updating the website of the Vocational Training Corporation through the provision of database especially for the beneficiaries of the Institutes of trainees, trainers and owners of the labor market and the stakeholders, where all the information related to them can be stored, also studying and analyzing of data associated with them, to support the operations of setting priorities based on the Six Sigma methodology, this database helps institutions in the formulation of policy dealing with their beneficiaries, meet their demands, check their expectations and to find their satisfaction, the results of this study agreed with the study of (Motwani \& Antony, 2004).

The results showed that the field of (Work Mechanism) came in the sixth and final rank, with an arithmetic mean of (2.287), this result indicates that workers estimate in the vocational and technical training institutes to apply the Six Sigma methodology came in a low degree, this may be attributed to differences in the organizational culture of the workers, from administrators and teachers and trainers, therefore it must form a unified regulatory environment that include the principles, values and concepts regarding the Six Sigma methodology, which must prevail in vocational training institutes for all employees, so they can understand the new changes, so the senior leadership of the vocational training corporation when applying the Six Sigma methodology, must work on a new internal and external organizational culture, which can agree with new methodology and the environmental variables, which help in achieving its new mission and strategy, and make it unable to solve their problems effectively within Six Sigma methodology in case of its application, through the participation of workers in their problems and solve the problems related to work and the participation of workers in decision-making and a willingness to form a Six Sigma team system to provide direct contact with qualified trainers for the Six Sigma program, this study agreed with the study of (Motwani \& Antony, 2004).

\subsection{Results and Discussion of the Second Question}

Which states: Are there statistically significant differences in the significance level of $(0.05 \geq \alpha)$ estimate 
the degree of the effective use of Six Sigma system in the development of administrative performance institutes of vocational and technical training in Jordan according to Job Title variable (manager, teacher, trainer)?.

To answer this question, unitary variance analysis has been used for the sample of the study estimates from the workers in the vocational training institutes for each field of study and for the tool as a whole according to Job title of them. Table (4) illustrates this.

Table 4. Unitary variance analysis for the sample of the study estimations in using six sigma system in the development of administrative performance institutes of vocational and technical training in Jordan according to Job title for workers

\begin{tabular}{|c|c|c|c|c|c|c|}
\hline Fields & Source of Variation & $\begin{array}{c}\text { Sum of } \\
\text { Squares }\end{array}$ & $\begin{array}{c}\text { Freedom } \\
\text { Degree }\end{array}$ & $\begin{array}{c}\text { Squares } \\
\text { Mean }\end{array}$ & $\mathbf{F}$ & $\begin{array}{c}\text { Significance } \\
\text { Level }\end{array}$ \\
\hline \multirow{3}{*}{$\begin{array}{l}\text { Support and } \\
\text { Commitment of } \\
\text { Senior Leadership }\end{array}$} & Between the groups & 0.845 & 2 & 0.422 & \multirow{3}{*}{0.745} & \multirow{3}{*}{0.483} \\
\hline & Within the total groups & 165.478 & 271 & 0.677 & & \\
\hline & Total & 166.323 & 273273 & & & \\
\hline \multirow{3}{*}{$\begin{array}{l}\text { Human Resources } \\
\text { Management }\end{array}$} & Between the groups & 0.029 & 2 & 0.514 & & \\
\hline & Within the total groups & 175.841 & 271 & 0.694 & 0.022 & 0.985 \\
\hline & Total & 175.870 & 273 & & & \\
\hline \multirow{3}{*}{$\begin{array}{l}\text { Management } \\
\text { Information } \\
\text { Systems }\end{array}$} & Between the groups & 1.033 & 2 & 0.517 & & \\
\hline & Within the total groups & 127.785 & 271 & 0.489 & 1.057 & 0.353 \\
\hline & Total & 128.818 & 273 & & & \\
\hline \multirow[t]{3}{*}{ Work Mechanism } & Between the groups & 2.59 & 2 & 1.295 & & \\
\hline & Within the total groups & 198.66 & 271 & 0.283 & 4.66 & 0.01 \\
\hline & Total & 201.250 & 273 & & & \\
\hline \multirow[t]{3}{*}{ Practical Training } & Between the groups & 0.689 & 2 & 0.345 & & \\
\hline & Within the total groups & 141.615 & 271 & 0.039 & & \\
\hline & Total & 142.304 & 273 & & & \\
\hline \multirow{3}{*}{$\begin{array}{l}\text { Beneficiaries' } \\
\text { Satisfaction }\end{array}$} & Between the groups & 1.1730 & 2 & 0.866 & & \\
\hline & Within the total groups & 83.951 & 271 & 0.721 & 0.911 & 0.411 \\
\hline & Total & 185.124 & 273 & & & \\
\hline \multirow[t]{3}{*}{ Tool as a whole } & Between the groups & 0.525 & 2 & 0.261 & & \\
\hline & Within the total groups & 108.553 & 271 & 0.481 & 0.654 & 0.581 \\
\hline & Total & 109.078 & 273 & & & \\
\hline
\end{tabular}

* Statistically significant $(0.05=\infty)$

It is shown from table (4) the lack of statistically significant differences on significance level of $(0.05 \geq \alpha)$ of the tool as a whole and the study fields, except (Work Mechanism) field statistically, which was indicative.

To determine between any of the job title of workers (Administrator, Teacher and Trainer) the differences in the degree of readiness were applied to Six Sigma work mechanism, Scheffe' test was used. Table (5) shows that.

Table 5. Scheffe' test

\begin{tabular}{|c|c|c|c|c|}
\hline Job Title for workers & The arithmetic Mean & Administrator & Teacher & Trainer \\
\hline Administrator & 3.839 & & ** & $* *$ \\
\hline Teacher & 3.498 & $* *$ & & \\
\hline Trainer & 3.522 & $* *$ & & \\
\hline
\end{tabular}

$*$ A function of the level $(0.05=\alpha)$ 
It is noted from table (5) the existence of statistically significant differences on significance level of $(0.05 \geq \alpha)$ between the means of the staff estimations for the administrators, with teachers and trainers to the field of work mechanism, where the arithmetic mean was (3.839) this may be attributed to what administrators in vocational training institutes enjoyed of high capacity to exercise their role effectively and efficiently and inform them of capacity and knowledge, as they receive numerous training courses related to overall quality programs and their guarantee, including Six Sigma methodology.

\subsection{The Results of the Third Question}

Which states: Are there any statistically significant differences in the significance level of $(0.05 \geq \alpha)$ estimate of the effective use of Six Sigma system degree in the development of administrative performance for institutes of vocational and technical training in Jordan depending on the years of experience variable (less than 5 years, 5-10 years, more than 10 years)?. And to answer this question, unified variance analysis has been used for the study sample estimates from workers in the vocational training institutes for each field of study and for the tool as a whole according to the variable years of experience. Table (6) shows that.

Table 6. Unitary variance analysis for the sample of the study estimations in using Six Sigma system in the development of administrative performance institutes of vocational and technical training in Jordan according to years of experience for workers

\begin{tabular}{|c|c|c|c|c|c|c|}
\hline Fields & Source of Variation & $\begin{array}{c}\text { Sum of } \\
\text { Squares }\end{array}$ & $\begin{array}{c}\text { Freedom } \\
\text { Degree }\end{array}$ & $\begin{array}{c}\text { Squares } \\
\text { Mean }\end{array}$ & $\mathbf{F}$ & $\begin{array}{c}\text { Significance } \\
\text { Level }\end{array}$ \\
\hline \multirow{3}{*}{$\begin{array}{l}\text { Support and } \\
\text { Commitment of } \\
\text { Senior Leadership }\end{array}$} & Between the groups & 0.882 & 2 & 0.441 & & \\
\hline & Within the total groups & 171.441 & 271 & 0.685 & 0.663 & 0.521 \\
\hline & Total & 172.323 & 273 & & & \\
\hline \multirow{3}{*}{$\begin{array}{l}\text { Human Resources } \\
\text { Management }\end{array}$} & Between the groups & 1.489 & 2 & 0.745 & & \\
\hline & Within the total groups & 147.302 & 271 & 0.579 & 1.296 & 0.279 \\
\hline & Total & 148.791 & 273 & & & \\
\hline \multirow{3}{*}{$\begin{array}{l}\text { Management Information } \\
\text { Systems }\end{array}$} & Between the groups & 0.252 & 2 & 0.126 & & \\
\hline & Within the total groups & 127.275 & 271 & 0.491 & 0.65 & 0.773 \\
\hline & Total & 127.527 & 273 & & & \\
\hline \multirow[t]{3}{*}{ Work Mechanism } & Between the groups & 1.059 & 2 & 0.527 & & \\
\hline & Within the total groups & 123.943 & 271 & 0.747 & 1.112 & 0.336 \\
\hline & Total & 125.002 & 273 & & & \\
\hline \multirow[t]{3}{*}{ Practical Training } & Between the groups & 1.151 & 2 & 0.579 & & \\
\hline & Within the total groups & 1034.191 & 271 & 0.528 & 1.094 & 0.331 \\
\hline & Total & 135.342 & 273 & & & \\
\hline \multirow[t]{3}{*}{ Beneficiaries' Satisfaction } & Between the groups & 2.181 & 2 & 1.091 & & \\
\hline & Within the total groups & 145.372 & 271 & 0.567 & 1.927 & 0.147 \\
\hline & Total & 147.553 & 273 & & & \\
\hline \multirow[t]{3}{*}{ Tool as a whole } & Between the groups & 1.179 & 2 & 0.589 & & \\
\hline & Within the total groups & 107.324 & 271 & 0.425 & 1.416 & 0.251 \\
\hline & Total & 108.503 & 273 & & & \\
\hline
\end{tabular}

* Statistically significant level of $(0.05=\not{\alpha})$

It is shown from table (6) the lack of statistically significant differences on significance level of $(0.05 \geq \alpha)$ of the tool as a whole and the study field in the estimates of workers in the institutes of vocational and technical training for the application of Six Sigma variable depending on experience, as the result may indicate that the application of Six Sigma system for workers, administrators, teachers and trainers all are close as a new 
methodology and culture for workers and its reflection which applied to workers in vocational training corporations itself, as experience in the field of employment and its specialties have nothing to do with expertise in the application of the Six Sigma methodology acquired through training because of the novelty of this methodology and the mechanism of applying it, regardless of years of experience.

\section{Recommendations}

In light of the results of the study, we can conclude the following recommendations:

- The Vocational Training Corporation is applying Six Sigma test methodology on a number of affiliated corporations, then work to protect that experience and applying it to all corporations later.

- Work on the development of organizational culture based on quality control and confirmation of all workers in vocational and technical training institutes and most important is cooperation, teamwork and the application of work mechanism and methodology to Six Sigma.

- Applying further studies and research on the application of the Six Sigma system methodology on Jordanian schools and universities, so that it can address the communities, factors and variables that the study didn't address.

\section{References}

Al-Khawaja, M. (2008). Developing a model for the re-engineering of administrative processes in the Vocational Training Corporation in Jordan. Doctor of Philosophy Thesis, University of Jordan. Retrieved from http://theses.ju.edu.jo/th.aspx

Al-Rihani, S. (2010). The possibility of applying the principles of Six Sigma and its constraints in the school administration in the State of Kuwait's schools. Educational Journal, 96, 15-19.

Al-Shaman, A. (2005). Implementing six Sigma in Education. Journal of King Saud University, Educational Sciences \& Islamic Studies, 18(1), 98-136.

Antony. (2004). Some Pros and Cons of Sigma: an Academe Perspective. The TQM Magazine, 16(4), 33-306.

Bin Saeed, Khalid. (2004). Six Sigma Applications on the Industrial and Service Facilities (1st ed). Riyadh: Alshegrey Press.

Coronad, R., \& Antony, J. (2002). Critical Success Factors for the successful implementation of Six Sigma Projects in organizations. TQM Magazine, 14(3), 90-120.

Eckes, G. (2000). The Six Sigma Revolution. New York: John Wiley \& sons.

Garrison, R., Noreen, E., \& Brewer, P. (2009). Managerial Accounting $\left(13^{\text {th }}\right.$ ed.). New York: McGraw-Hill.

Goetsch, D., \& Davis S. (1994). Introduction to Total Quality: Quality, Productivity, Competitiveness. Prentice-Hal, New Jersey.

Goh, T. (2004). Improving on the Six Sigma Paradigm. TQM Magazine, 16(4), 220-250.

Hung, HC., \& Sung, MH. (2011). Appling six sigma to manufacturing processes in the food industry to reduce quality cost. Scientific Research and Essays, 6(3), 580-591.

Jenicke, L., Kumar A., \& Holmes M. (2008). A framework for applying Six Sigma improvement methodology in an academic environment. The times Journal, 20(5), 453-462.

Kreisder, K. (2006). Employee expectancies for six sigma success. Leadership \& Organization Development Journal, 27(1), 28-37.

Motwanim J., \& Antony, J. (2004). A business Process Change Framework for Examining the implementation of Six Sigma: A Case Study of Dow Chemical's. The TQM Magazine, 16(4), 273-283.

National Agenda. (2005). Jordan that we want (2006-2015) document 4/7, the aspect of supporting employment and vocational training. Retrieved from www.mol.gov.jo/LinkClick.aspx?fileticket=ZVHbhZp0Ba8\%3D

Pande, P., \& Holpp , L. (2001). What is six Sigma? (1 ${ }^{\text {st }}$ ed.). New York: McGraw-Hill.

Pardee, Ron. (2007). Implementing Six Sigma Efforts. Retrieved from www.eric.ed.gov/PDFS/ED490415.pdf

Patil, V. H. (2006). Six Sigma in Education: To Achieve Overall Excellence in the Field of Education. Third International Conference on Information Technology: New Generations. Las Vegas, NV.

Pie-Shih H. S. (2006). The Effect of Six Sigma Implementation Practices on Business Performance. Master Thesis, University of Tatung. 
Raisinghani. M. (2005). Six Sigma Concepts, Tools, and Applications. Industrial Management \& Data Systems, $105(4), 480-500$.

Theodore, G. (2008). Development and Reforming of the Vocational Training Corporation Project. Restructuring the Institution Report, Vocational Training Corporation documents. Retrieved from http://www.vtc.gov.jo

Vocational Training Corporation. (2011). Annual Report. Amman, Jordan.

Weinstein L. (2006). Integrating six sigma concepts. Journal of Educational Research, 16(5), 17-28.

$\mathrm{Zu}, \mathrm{X}$., Fredendall, L., \& Robbins, T. (2006). Organizational culture and quality practices in six sigma. The 2006 annual meeting of the academy of management, Atlanta. 